\title{
INSPIREE:
}

\section{Managing Arthritis Joint Pain and Hypertension in Elderly with Health Education Video}

doi) https://doi.org/10.53905/inspiree.v2i2.42

*Weeke Budhyanti1abcde, Lucky Anggiat ${ }^{1 c d} \mathbb{D}$, Citra Puspa Juwita1cde

${ }^{1}$ Program Studi Fisioterapi, Fakultas Vokasi, Universitas Kristen Indonesia, Jakarta, Indonesia.

The purpose of the study. Arthritis of the joint and hypertension are two conditions that the elderly are prone to face. Both of these conditions affect the movement and function of the human body. The Physiotherapy study program considers it important to continue to provide service to the elderly community in Kelurahan Cawang, which is a fostered area of the Fakultas Vokasi.

Materials and methods. Program socialization with health education videos for the elderly exercises for arthritis pain and hypertension were options to continue providing community service during a pandemic. Empowerment of public health agents and families is also carried out to disseminate information about the health of the elderly in terms of hypertension and arthritis pain which are prepared by lecturers of the physiotherapy study program.

Results. With the health educational video, the elderly still pay attention to their health even though they are not as effective as usual.

Conclusions. As the conclusion, the elderly still felt helped and were enthusiastic about participating in the health educational videos provided by the lecturers.

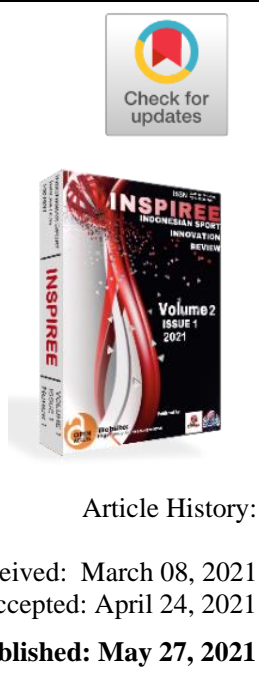

PENDAHULUAN

Lansia merupakan proses dari kehidupan yang akan dialami oleh setiap orang. Seiring dengan pertambahan usia, kondisi kesehatan lansia merupakan hal yang perlu diperhatikan karena adanya perubahan baik secara fisik, psikis dan metal yang bersifat fisiologis. BPS menyimpulkan satu dari empat lansia memiliki gangguan kesehatan secara umum sekalipun hal tersebut merupakan perbandingan yang menurun sejak lima tahun terakhir (Badan Pusat Statistik, 2019). Fenomena penuaan penduduk saat ini menjadi tantangan di Indonesia. Hal ini dapat dikarenakan dengan semakin tingginya harapan hidup manusia di Indonesia. Hidup lebih lama belum tentu berarti hidup dalam kondisi sehat. Prevalensi penyakit pada lansia mengalami peningkatan dari waktu ke waktu. Hal ini dikarenakan kerentanan terhadap penyakit dan disabilitas meningkat seiring dengan usia (Muzamil \& Martini, 2014). 
Penurunan kondisi fisik lansia menjadi salah satu hal yang akan nampak dari setiap manusia seperti penurunan tinggi badan, berat badan dan kekuatan otot (Sirey et al., 2005). Problem yang terkadang muncul pada lansia adalah kemunduran fungsi tubuh seperti penurunan kapasitas fisik dengan tanda penurunan massa otot dan kekuatan, penurunan denyut jantung maksimal, peningkatan lemak yang ada dalam tubuh juga dengan penurunan fungsi otak atau kognitif (Junaidi, 2011). Kondisi gerak dan fungsi yang paling nampak pada lansia adalah kondisi dimana lansia merasakan nyeri serta gangguan gerak pada sendi. Dari sebuah laporan pengabdian kepada masyarakat yang dilakukan dosen program studi fisioterapi Universitas Kristen Indonesia pada warga lansia di salah satu gereja di daerah Bogor menunjukkan bahwa terdapat gangguan gerak dan fungsi pada bahu, leher, pinggang, lutut dan kaki (Manik et al., 2019). Selain itu, dalam laporan tersebut juga terdapat gangguan fungsi pernafasan dengan permasalahan gangguan gerak lainnya yang terjadi pada persarafan. Dalam perkembangannya, tubuh dari insan lansia juga akan terjadi terjadi penurunan kondisi kardiovaskular seperti kurangnya elastisitas dari dinding aorta. Perubahan dari lainnya juga terjadi seperti terjadi penurunan ukuran dari organ-organ tubuh tetapi tidak pada jantung. Secara umum, ukuran jantung pada insan lansia akan membesar. Dengan demikian, perubahan ini berkaitan dengan kelainan pada sistem kardiovaskuler yang akan menyebabkan gangguan pada tekanan darah seperti hipertensi (Laka et al., 2018).

Dalam kesehariannya, lansia dilaporkan kurang melakukan pergerakan fisik yang cukup atau dalam kondisi tidak aktif (Santoso \& Rohmah, 2011). Pemaparan oleh Stanhope \& Jeanette, 2019 menyatakan bahwa ada resiko biologis terkait lansia dengan penururnan fungsi biologis akibat penuaan. Resiko lain yang dinyatakan adalah risiko sosial dan lingkungan pada yang dapat memicu stress (Jee \& Lee, 2013). Selain itu, terdapat gangguan juga dalam aspek ekonomi pada lansia karena menurunnya pendapatan setelah pensiun. Lebih lanjut lagi, risiko gaya hidup dan perilaku juga memengaruhi kondisi kesehatan lansia seperti seperti kurangnya aktivitas fisik dan konsumsi makanan yang tidak sehat dapat memicu terjadinya penyakit dan juga dapat mengarah kepada kematian (Saleh, 1975). 
Dalam bidang pelayanan lansia diharapkan ditingkatkan seiring dengan penurunan kondisi metabolisme tubuh pada lansia. Dengan demikian, diharapkan lansia dapat merasa nyaman baik secara fisik maupun psikologis dalam kehidupan bermasyarakat serta mengakualisasikan kehidupannya (Badan Pusat Statistik, 2019). Untuk memenuhi harapan tersebut, dinilai perlu dilakukan edukasi baik pengenalan tentang kondisi fisik lansia secara umum, pengetahuan penyakit degeneratif pada lansia dalam aspek gerak dan fungsi serta kardiorespirasi.

Latihan fisik sangat penting bagi lansia dalam meningkatkan kualitas hidupnya. Sebuah penelitian penelaahan literatur menyatakan bahwa latihan pada kelompok lansia dapat memberikan efek yang baik pada perubahan kondisi fisik lansia (Afriwardi, 2009). Dengan latihan yang teratur hubungan sosial, kesehatan fisik dan kesehatan mental pada lansia akan meningkat. Selain itu, dengan latihan, diharapkan dapat memberikan pengaruh dalam pengurangan risiko penyakit serta memelihara gerak dan fungsi tubuh lansia (Afriwardi, 2009; Kusnanto et al., 2010). Latihan dapat mencegah kelelahan fisik karena meningkatkan fungsi kardiovaskuler, sistem saraf pusat, sistem imun dan sistem endokrin serta menurunkan gejala depresi (Junaidi, 2011; Rohana, 2011). Dalam kondisi pademi Covid 19, sangat diperlukan latihan agar insan lansia tidak mengalami penuruan kemampuan motorik (Pardilla et al., 2020).

Efek latihan berpengaruh dalam komponen kebugaran lansia seperti kekuatan dan ketahanan otot, kemampuan jantung paru, kelenturan otot, komposisi lemak tubuh, keseimbangan (Fitri \& Zukar, 2021). Lebih lanjut, dalam penelitian tersebut menyatakan dengan latihan yang proporsional dapat memperlambat proses penuaan pada lansia. Dari latar belakang diatas maka dipandang perlu untuk melakukan pengabdian kepada masyarakat (PKM) pada kelompok bina lansia atau puskesmas kelompok lansia. Kegiatan PkM bertujuan untuk memberikan edukasi tentang kondisi umum kesehatan lansia, perubahan fisik dan gangguan gerak fungsi lansia, serta perubahan kondisi kardiorespirasi pada lansia. Selain itu, penyuluhan berkelanjutan dilakukan dalam PkM berupa penanganan awal gangguan gerak dan fungsi tubuh serta peningkatan kebugaran kardiorespirasi menggunakan latihan sederhana pada lansia dan kader lansia. 


\section{METODOLOGI}

Pelaksanaan studi kegiatan sosialisasi pengabdian kepada masyarakat dilakukan secara dalam jaringan (daring) karena selama pandemi terjadi pembatasan fisik dan posyandu belum diaktifkan. Tim penulis menyusun video edukasi yang diunggah ke kanal youtube resmi dari Program Studi Fisioterapi Fakultas Vokasi Universitas Kristen Indonesia. Ada tiga video yang dibuat, yaitu Edukasi Gaya Hidup Sehat Bagi Lansia (bit.ly/EdukasiLansiaSehat), Latihan mandiri Penanganan Pengapuran (bit.ly/PencegahanPengapuran), dan Edukasi Gerak Untuk Pengendalian Tekanan Darah (bit.ly/EdukasiHipert).

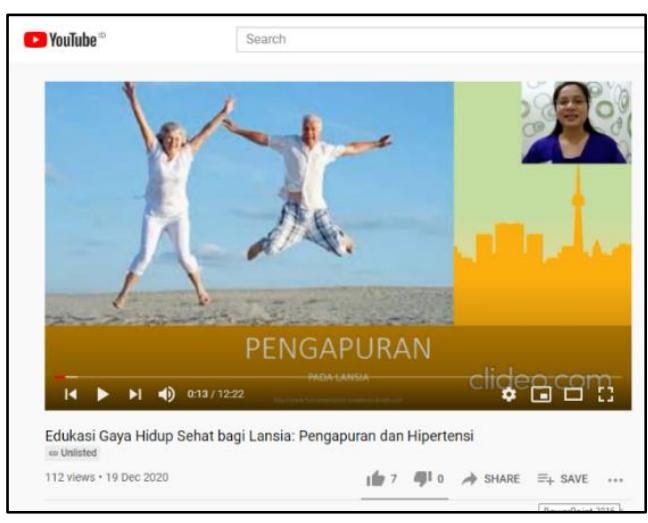

Gambar 1. Cuplikan Video Edukasi Gaya Hidup Sehat (bit.ly/EdukasiLansiaSehat)

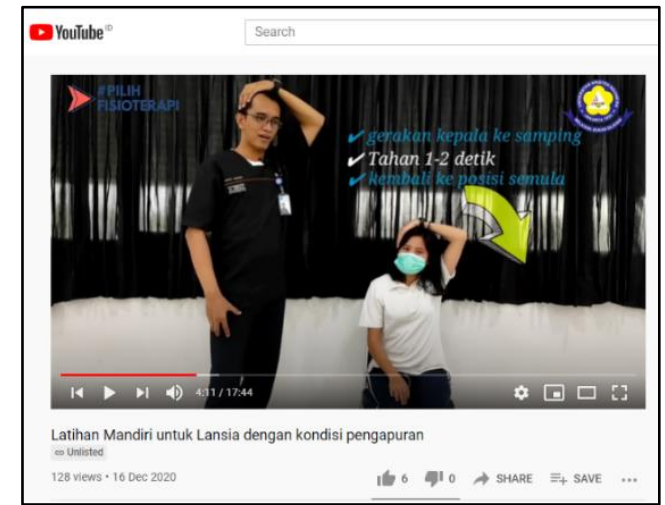

Gambar 2. Cuplikan Video Latihan mandiri Penanganan Pengapuran (bit.ly/PencegahanPengapuran)

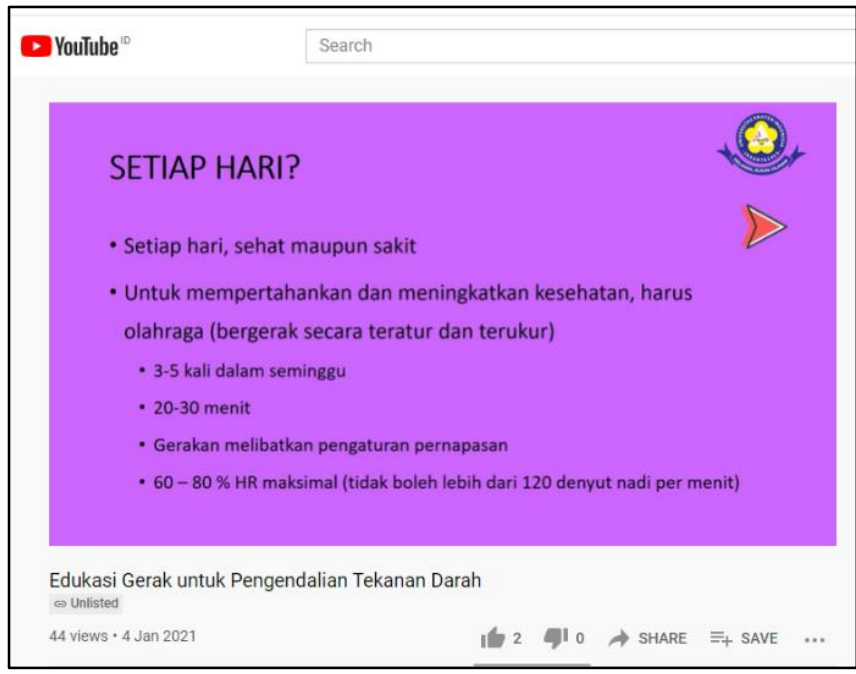

Gambar 3. Edukasi Gerak Untuk Pengendalian Tekanan Darah (bit.ly/EdukasiHipert).

Video Edukasi Gaya Hidup Sehat Bagi Lansia berisikan edukasi tentang pengaturan gaya hidup, pola makan, batasan-batasan gaya hidup bagi lansia, ulasan tentang pengapuran dan ulasan terkait hipertensi. Video edukasi gaya hidup sehat diadopsi dari penjelasan tentang kehidupan lansia oleh Kementerian Kesehatan. Video Latihan Mandiri untuk Lansia dengan Kondisi Pengapuran selain mencakup edukasi tentang pengapuran juga menyampaikan demonstrasi gerak yang dapat dicontoh oleh 
Managing Arthritis Joint Pain and Hypertension In Elderly With Health Education Video.

lansia. Latihan mandiri yang disiapkan dalam video merupakan bagian dari pembelajaran terapi latihan yang sudah diakui keefektifannya dalam pengurangan nyeri pada kondisi pengapuran. Video Edukasi Gerak Untuk Pengendalian Tekanan Darah menyampaikan agar gerakan yang didemonstrasikan pada Video Gerak Pencegahan Pengapuran dilakukan secara teratur agar dapat meningkatkan kesehatan pembuluh darah. Dengan didasari video latihan, diharapkan lansia dapat terus menjaga kesehatan dalam hal tekanan darah dan ditambah dengan kesehatan gerak dan fungsi sendi yang kemungkinan besar terjadi pengapuran

Ketiga tautan video disampaikan kepada kader melalui whatsapp messenger, lalu kader mengirimkan tautan video tersebut kepada lansia di wilayah binaannya. Selain dititipkan kepada kader, $Q R$ Code untuk tautan yang mengarahkan kepada video dicetak pada standing banner yang dititipkan di Toko Rina yang berada di daerah tempat tinggal lansia. Dengan demikian orang yang melintas atau berbelanja dapat diingatkan dan mengakses video.

\section{HASIL PENELITIAN}

Metode penyampaian edukasi dengan melepas video kepada kader awalnya diragukan oleh tim, karena khawatir kader tidak menyampaikan amanah tersebut. Namun dalam pelaksanaannya ternyata kader melaporkan kegiatan penyampaian video. Bahkan dikirimkan video lansia yang sedang menonton video bersama-sama sambil tetap menjalankan protokol kesehatan. Kader juga menyampaikan diskusidiskusi yang muncul dari lansia terkait video yang ditonton.

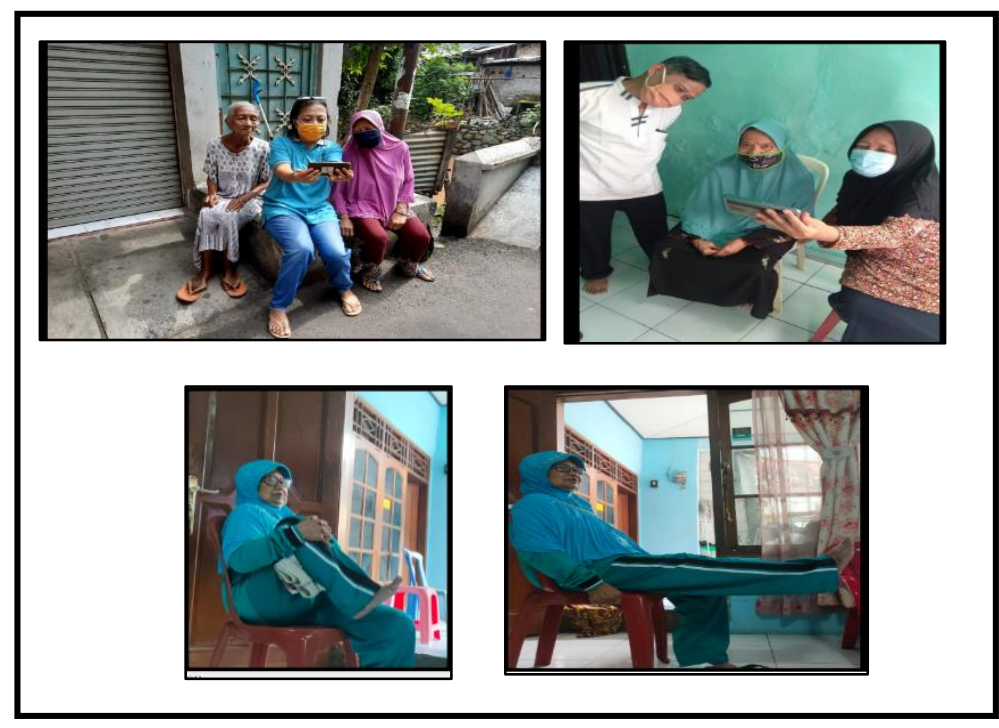

Gambar 4. Penyampaian video edukasi dan lansia yang melakukan latihan dari video 
Terlihat dalam gambar, lansia sangat antusias dalam mengikuti latihan yang didasarkan pada video. Demikian pula para kader yang diminta menyampaikan hal-hal terkait video yang mungkin tidak dipahami kepada lansia. Dari video yang diunggah ke kanal youtube dapat dilihat bahwa cukup banyak penonton (viewers) yang melihat video. Data penonton dapat di tabel berikut

Tabel 1. Data penonton Edukasi Video

\begin{tabular}{ll}
\hline Judul Video & Jumlah Penonton (Per 2 Februari 2021) \\
\hline Edukasi Gaya Hidup Sehat & 112 Penonton \\
Latihan mandiri Penanganan Pengapuran & 128 Penonton \\
Edukasi Gerak Untuk Pengendalian Tekanan Darah & 44 Penonton \\
\hline
\end{tabular}

Meskipun tidak diketahui secara jelas apakah penonton adalah lansia target dari tim dosen, namun dapat diasumsikan video ditonton oleh masyarakat baik lansia target dari tim dosen maupun tidak. Sehingga, kebermanfaatan video tetap dirasakan masyarakat secara umum maupun khusus pada lansia.

\section{PEMBAHASAN}

Situasi pandemi ini menyebabkan lansia mengalami pembatasan kegiatan, sehingga kerinduan lansia untuk mengakses pengetahuan dan usaha peningkatan kesehatan sangat besar. Usaha edukasi secara daring bagi lansia dapat menjadi salah satu jawaban untuk menjawab kebutuhan tersebut. Dari dokumentasi yang didapatkan oleh kader, terlihat kader juga memerlukan pengajaran terlebih dahulu agar informasi dari video dapat disampaikan lebih baik. Jika kader diajarkan terlebih dahulu, ada kemungkinan para kader bisa menjadi penyalur informasi dengan lebih baik pada lansia yang memiliki gangguan audio visual.

Dari hasil penonton pada kanal youtube, dapat dilihat bahwa ketiga video ditonton lebih dari 40 penonton. Kanal youtube fisioterapi dapat menjadi solusi yang baik agar video dapat di tonton terus dan berulang-ulang. Namun, target penonton lansia masih belum dapat dilaporkan karena keterbatasan kemampuan kanal youtube. Selain itu, dapat diperhatikan juga, video dengan bentuk gerak manusia mempunyai penonton yang lebih banyak. Sehingga dapat diasumsikan, video yang diberikan pada lansia dapat berupa gerakan manusia yang dapat ditiru. Selain melatih daya ingat, dengan video latihan dapat memberi pengaruh baik pada kondisi gangguan gerak dan fungsi pada lansia. Latihan di rumah diharapkan dapat mengurangi nyeri sendi pada pengapuran sama halnya dengan nyeri sendi pada umumnya (Budhyanti et al., 2020). 
KESIMPULAN

Edukasi dengan metode audiovisual masih dapat dilanjutkan untuk meningkatkan kualitas kesehatan lansia. Penggunaan video berbentuk gerakan latihan dapat digunakan untuk meningkatkan minat penonton serta mempraktikkan gerakan latihan. Edukasi pada kader lansia juga diperlukan agar dapat memberikan informasi yang lebih baik pada lansia yang kemungkinan mempunyai gangguan audio visual.

\section{HAMBATAN DAN KENDALA}

Hambatan dalam pelaksanaan studi ini terkait tidak tersampaikan sosialisasi secara tatap muka karena adanya pembatasan kegiatan selama masa pandemi. Namun, tidak ada kendala yang berarti ketika dilakukan secara daring.

\section{PERNYATAAN RESMI}

Ucapan terima kasih kami sampaikan bagi Program Studi Fisioterapi, Fakultas Vokasi, Universitas Kristen Indonesia, Lembaga Penelitian dan Pengabdian pada Masyarakat UKI, Kelurahan Cawang dan Kader Lansia Kelurahan Cawang dalam kerjasamanya sehingga studi ini dapat berjalan dengan baik.

\section{DAFTAR PUSTAKA}

Adi Saputra, S. (2020). Giakusuki Pada Karate: Analisis Peran Kekuatan Otot Lengan Dan Otot Bahu: Giakusuki On Karate: Analysis Of The Role Of Arm Strength And Shoulder Muscles. INSPIREE: Indonesian Sport Innovation Review, 1(1), 24-35. https://doi.org/10.53905/inspiree.v1i1.5

Afriwardi. (2009). Program latihanbagi kelompok lansia. Jurnal Kesehatan Masyarakat, $3(1), 35-37$.

Badan Pusat Statistik. (2019). Statistik Penduduk Lanjut Usia.

Budhyanti, W., Anggiat, L., \& Juwita, C. P. (2020). Penanganan Dan Pencegahan Nyeri Leher Dan Punggung Bawah Dengan Peregangan Mandiri Pada Pegawai Sekolah

Menengah Kejuruan Negeri 10 Cawang: Program Pengabdian Kepada MasyarakaT. Jurnal Fisioterapi Dan Rehabilitas, 4(1), 79-89.

Bastian, Y. (2020). Efek Daya Ledak Otot Tungkai Dan Motivasi Berprestasi Dalam Keterampilan Smash Pada Atlet Bola Voli . INSPIREE: Indonesian Sport Innovation Review, 1(2), 89-104. https://doi.org/10.53905/inspiree.v1i2.12 Harika Fitri, A. ., \& Ricky, Z. (2021). The Effect of Endurance Training on Vo2max Futsal 
Athletes MAN 1 Dharmasraya . INSPIREE: Indonesian Sport Innovation Review, 2(1),

01-07. https://doi.org/10.53905/inspiree.v2i1.26

Iqbal, M. (2020). The Limb Explosive Power and Goal Target Accuracy on Futsal Playing Skills: Correlational Analysis Study: Poweri Otot Tungkai dan Akurasi Sasaran dalam Keterampilan Bermain Futsal: Studi Analisis Korelasional. INSPIREE: Indonesian Sport Innovation Review, 1(1), 1-8. https://doi.org/10.53905/inspiree.v1i1.1

Jee, Y. J., \& Lee, Y. B. (2013). Factors influencing depression among elderly patients in geriatric hospitals. Journal of Physical Therapy Science, 25(11), 1445-1449. https://doi.org/10.1589/jpts.25.1445

Junaidi, S. (2011). Pembinaan Fisik Lansia melalui Aktivitas Olahraga Jalan Kaki. Media Ilmu Keolahragaan Indonesia, 1(1). https://doi.org/10.15294/miki.v1i1.1130

Kusnanto, K., Indarwati, R., \& Mufidah, N. (2010). Peningkatan Stabilitas Postural Pada Lansia Melalui Balance Exercise. Nurse Media Journal of Nursing, 1(2), 59-68. https://doi.org/10.14710/nmjn.v1i2.716

Laka, O. K., Widodo, D., \& Rahayu H., W. (2018). Hubungan Hipertensi dengan Tingkat Kecemasan pada Lansia di Posyandu Lansia Desa Banjarejo Kecamatan Ngantang $\begin{array}{llll}\text { Malang. Nursing } \quad \text { 22-32. } & \text { News, }\end{array}$ https://publikasi.unitri.ac.id/index.php/fikes/article/view/749

Manik, J. W. H., Rahmansyah, B., Anggiat, L., Weeke, B., Manurung, N. S. A., Napitupulu, R. M., Citra Puspa, J., Bisa, M., \& Lisnaini, L. (2019). Pemeriksaan Kondisi Gerak dan Fungsi dan Penanganan Fisioterapi Pada Lansia Di Gereja Bethel Indonesia Jemaat Danau Bogor. Jurnal Comunita Servizio, 1(2), 109-119.

Muzamil, M. S., \& Martini, R. D. (2014). Hubungan Antara Tingkat Aktivitas Fisik dengan Fungsi Kognitif pada Usila di Kelurahan Jati Kecamatan Padang Timur. Jurnal Kesehatan Andalas, 3(2), 202-205.

Pardilla, H. ., Henjilito, R. ., Asilestari, P. ., \& Husnayadi, I. . (2020). Decreased Athlete Motor Skills: Before And After Activity Coronavirus Disease (Covid-19) Pandemic. INSPIREE: Indonesian Sport Innovation Review, 1(2), 57-65. https://doi.org/10.53905/inspiree.v1i2.6

Rohana, S. (2011). Senam Vitalisasi Otak Lebih Meningkatkan Fungsi kognitif kelompok 
lansia dari pada senam lansia di balai perlindungan Sosial Propinsi Banten. Jurnal Fisioterapi, 11(1), 15-35.

Saleh, R. M. (1975). document (4).pdf. Berkala Ilmu Kedokteran Gajah Mada, 7(3).

Santoso, T. B., \& Rohmah, A. S. N. (2011). Gangguan gerak dan fungsi kognitif pada wanita lanjut usia. Jurnal Kesehatan, ISSN, 4(1), 41-57.

Sirey, J. A., Bruce, M. L., \& Alexopoulos, G. S. (2005). The treatment initiation program: An intervention to improve depression outcomes in older adults. American Journal of Psychiatry, 162(1), 184-186. https://doi.org/10.1176/appi.ajp.162.1.184

Stanhope, M., \& Jeanette, L. (2019). Public Health Nursing (10th ed.). Elsevier. https://www.elsevier.com/books/public-health-nursing/stanhope/978-0-323$58224-7$ 


\section{LAMPIRAN}

Information About The Authors:

\section{Informasi Tentang Penulis:}

\section{Weeke Budhyanti, SSt.Ft., S.Ft., M.Biomed:}

Email: weekeb@uki.ac.id;Program Studi Fisioterapi, Fakultas Vokasi, Universitas Kristen Indonesia.

\section{Lucky Anggiat, STr.Ft., M.Physio:}

Email; lucky.panjaitan@uki.ac.id;Program Studi Fisioterapi, Fakultas Vokasi, Universitas Kristen Indonesia.

\section{Citra Puspa Juwita, SKM., MKM:}

Email; citra.simatupang@uki.ac.id;Program Studi Fisioterapi, Fakultas Vokasi, Universitas Kristen Indonesia. 